\title{
Developmental changes in the use of categorization as a study strategy
}

\author{
CURTIS W. McINTYRE \\ Southern Methodist University, Dallas, Texas 75275 \\ CHRISTOPHER T. WEAVER \\ Florida Southern College, Lakeland, Florida 33802 \\ and \\ EUGENE A. LOVELACE and RICHARD S. NISKA \\ University of Virginia, Charlottesville, Virginia 22903
}

\begin{abstract}
Kindergarten, third-grade, fifth-grade, and college subjects were asked to memorize a single set of randomly arrayed items containing readily identifiable categories. The items were available during four trials, each trial consisting of a 30 -sec study period followed by a free recall test. Preceding the last three trials, each subject was allowed to select one-third of the to-beremembered items for study but was asked to attempt recall of all the items. The strategy of selecting items from the same category for study was rarely used spontaneously by kindergartners but was used by the older subjects. Efficiency comparisons suggested that this strategy would prove useful to kindergartners if used by them.
\end{abstract}

Only recently has specific interest been shown in the study strategies used by children during simple memory tasks. In an examination of one of the most elementary study strategies, selecting items for study that had been missed during a previous recall trial, Masur, McIntyre, and Flavell (1973) found that children did not concentrate their study activities on missed items until about the third grade. Similarly, other research has indicated that the use of a slightly more complicated study strategy, grouping to-be-remembered (TBR) items for study on the basis of semantic similarities (categorization), may also not emerge until the third grade (Appel, Cooper, McCarrell, Sims-Knight, Yussen, \& Flavell, 1972; Moely, Olson, Halwes, \& Flavell, 1969; Yussen, Gagné, Garguilo, \& Kunen, 1974). In contrast to these earlier studies, Salatas and Flavell (1976) reported evidence of the spontaneous use of categorization as a study strategy by first graders.

The present study is directed toward a closer examination of the spontaneous use by young children of categorization as a strategy for studying TBR items. The basic task involved four trials where kindergarten, thirdgrade, fifth-grade, and college subjects were asked to study and recall a group of items containing readily identifiable categories (e.g., animals, toys, or vegetables). Preceding the second, third, and fourth recall trials, each subject was allowed to select one-third of the TBR items for study. Of central interest was whether the children would select for study categories of items that had not been recalled previously.

\section{METHOD}

\section{Subjects}

Groups of 12 subjects (about half male and half female) were selected from a kindergarten (mean age $=6.3$ years), a third-grade (mean age $=8.6$ years), and a fifth-grade (mean age $=11.2$ years) class at a white middle-class elementary school and from a college introductory psychology class (mean age $=19.1$ years). The children were above average in academic ability.

\section{Materials}

All materials were pretested with nursery-school children to ensure that they were easily recognized, consistently named, and readily categorized.

Warm-up items. Fifteen small colored common objects, toys, and animals (e.g., a whistle, ball, horse, crayon) were used during the warm-up trials.

Experimental items. Forty-two black and white line drawings of common toys, animals, articles of clothing, body parts, fruits, and vehicles (e.g., kite, dog, shoe, ear, apple, and car) drawn from or similar to those available in the Peabody Picture Vocabulary Test were mounted on $3 \times 5$ in. index cards.

\section{Procedure}

Each subject was tested individually; when each set of items was first introduced, the subject was asked to name each item in turn. The items were always presented in a random array. A large black cloth was used to cover the items during recall and a stopwatch was used to time the study and recall periods. The subjects were encouraged to try their best throughout the experiment.

Warm-up phase. Each subject was told that he was going to "play a memory game," was shown the 15 warm-up items, named each, and was told that he would have a short time $(30 \mathrm{sec})$ to study them. He was told that the items would be 
covered at the end of the study period and that he would be asked to name them all. Two trials were given; the recall period began as soon as the items were covered and lasted until the subject indicated he had recalled all he could remember or 2 min had elapsed.

After the first recall period, the items were uncovered, and the subject was told he would be permitted to study only five (one-third) of the items, although he was to try to recall all of them. The experimenter made sure the subject understood he was to recall all the items, both those selected for study and those not. This was reemphasized during later trials. The subject named the items selected for study, and the experimenter removed the rest. Then the study and recall periods were repeated to complete the second warm-up trial.

Experimental phase. The subject was shown the experimental items (in a randomized order) and told the procedure would be the same. The kindergartners were shown 24 items, 6 categories of 4 items each. The third graders were shown 30 items, 6 categories of 5 items each. The fifth graders and college students were shown 42 items, 6 categores of 7 items each. The total number of stimulus items shown represents approximately three times the average "memory span" for each group, as determined in pilot work. The procedure during the four experimental trials was virtually identical to that during the warm-up phase. After each recall period, all the items were shown again so that each subject could select verbally the ones he wanted to study on the succeeding trial. Each subject was allowed to select onethird of the items for study. (This was equivalent to twice the individual category size.) The subjects' selection preferences and recall performances were tape-recorded.

\section{RESULTS AND DISCUSSION}

The results obtained for recall performance will be presented and discussed briefly, followed by a more detailed presentation and discussion of the data of central interest, the selection for study preferences.

\section{Recall}

A 4 (age) by 4 (trials) analysis of variance of the number of items recalled revealed significant effects for age $[F(3,44)=87.98, p<.01]$, trials $[F(3,132)=53.44$. $\mathrm{p}<.01]$, and the Age by Trials interaction $[F(9,132)=$ $12.20, \mathrm{p}<.01]$. Newman-Keuls comparisons revealed the means for all four age groups differed significantly from each other $(p<.01)$; the means for the kindergarten, third, fifth, and adult groups were $6.88,14.73$, 19.06 , and 29.08 , respectively. Newman-Keuls comparisons revealed the mean number of items recalled on Trial 1 (13.17) was significantly less than on Trial 2 (16.71) which, in turn, was significantly less than on either Trials 3 or 4 (19.23 and 20.65 , respectively) $(p<.01)$. The significant Age by Trials interaction resulted from the unique recall pattern observed across trials for the kindergartners. Here, the number of items recalled did not increase across trials. A similar pattern of results was obtained from an analysis of variance of the percentage of possible items recalled.

Categorization. Categorization during recall was assessed by the ratio of repetition (Bousfield, 1953), which Frender and Doubilet (1974) suggested is "the best measure of clustering in free recall currently avail- able, and .... particularly useful for developmental research" (p. 66).

A 4 (age) by 4 (trials) analysis of variance of these ratios revealed significant effects for age $[F(3,44)=$ $26.12, \mathrm{p}<.01]$ and trials $[\mathrm{F}(3,132)=4.69, \mathrm{p}<.01]$, but no significant Age by Trials interaction. NewmanKeuls comparisons revealed all four age groups differed significantly from each other $(p<.01)$. The mean ratios of repetition obtained during recall increased from $.36, .45, .53$, to .76 , respectively, for the kindergarten, third, fifth, and adult groups. Although the mean ratios of repetition obtained during recall increased steadily from Trial 1 through Trial 4 (from $.47, .51, .55$, to .57 , respectively), Newman-Keuls comparisons revealed that the only significant difference was between Trials 1 and $4(p<.01)$. Sign tests revealed that the ratios of repetition during recall differed significantly from chance for each age group on each trial.

\section{Selection}

Missed items. To determine whether the subject was differentially selecting for study those items that had not been recalled on the immediately preceding trial, the proportion $(\mathrm{P})$ of unrecalled $(\overline{\mathrm{R}})$ items selected (S) $[\mathrm{P}(\mathrm{S} / \overline{\mathrm{R}})]$ was computed for each subject on each of Trials 2,3 , and 4 . This proportion was obtained by dividing the number of missed items that were actually selected for study by the number of missed items that could have been selected by that particular subject on that particular trial. A 4 (age) by 3 (trials) analysis of variance of these proportions revealed no significant differences.

The failure to obtain a significant difference for age observed in the present study departs from the results reported by Masur et al. (1973). They found their first grader's $\mathrm{P}(\mathrm{S} / \overline{\mathrm{R}})$ proportions $(\mathrm{M}=.62)$ to be significantly lower than those of both third graders $(M=80)$ and college subjects $(M=.85)$. Moreover, the mean values obtained for these proportions in the present experiment were somewhat lower than those in the Masur et al. study (see Table 1).

Efficiency scores. As in the Masur et al. (1973) study, four proportions were computed for each subject to assess the mnemonic value (or efficiency) of selecting for study previously missed vs. previously recalled items: (1) the mean proportion (averaged over trials) of items

Table 1

Mean Proportion [P(S/ $/ \bar{R})]$ of Unrecalled Items Selected for Study on Trials 2, 3, and 4

\begin{tabular}{lcccc}
\hline \multicolumn{1}{c}{ Age Groups } & Trial 2 & Trial 3 & Trial 4 & Mean \\
\hline Kindergarten & .63 & .71 & .69 & .67 \\
Third Grade & .58 & .55 & .58 & .57 \\
Fifth Grade & .60 & .63 & .52 & .58 \\
College & .64 & .59 & .68 & .64 \\
Mean & .61 & .62 & .62 & .62 \\
\hline
\end{tabular}


Table 2

Efficiency and Comparative Efficiency of Selecting vs. Not Selecting for Study Previously Recalled vs. Previously Unrecalled Items

\begin{tabular}{|c|c|c|c|c|c|c|c|}
\hline \multirow[b]{2}{*}{ Age Groups } & \multicolumn{4}{|c|}{ Efficiency } & \multicolumn{3}{|c|}{ Comparative Efficiency } \\
\hline & $\begin{array}{c}\mathrm{A} \\
\mathrm{P}(\mathrm{R} / \overline{\mathrm{R}} \mathrm{S})\end{array}$ & $\begin{array}{c}\mathrm{B} \\
\mathrm{P}(\mathrm{R} / \overline{\mathrm{RS}})\end{array}$ & $\begin{array}{c}\mathrm{C} \\
\mathrm{P}(\mathrm{R} / \mathrm{RS})\end{array}$ & $\begin{array}{c}D \\
P(R / R \bar{S})\end{array}$ & $\begin{array}{c}\mathrm{E} \\
\mathrm{A}-\mathrm{B} \\
\end{array}$ & $\begin{array}{c}F \\
C-D\end{array}$ & $\begin{array}{c}\mathrm{G} \\
\mathrm{E}-\mathrm{F}\end{array}$ \\
\hline $\begin{array}{l}\text { Kindergarten } \\
\text { Third Grade } \\
\text { Fifth Grade } \\
\text { College }\end{array}$ & $\begin{array}{l}.40 \\
.64 \\
.65 \\
.82\end{array}$ & $\begin{array}{l}.15 \\
.17 \\
.18 \\
.55\end{array}$ & $\begin{array}{l}.59 \\
.81 \\
.79 \\
.90\end{array}$ & $\begin{array}{l}.44 \\
.67 \\
.58 \\
.84\end{array}$ & $\begin{array}{l}.25 \\
.47 \\
.47 \\
.27\end{array}$ & $\begin{array}{l}.15 \\
.14 \\
.21 \\
.06\end{array}$ & $\begin{array}{l}.10 \\
.33 \\
.26 \\
.21\end{array}$ \\
\hline Mean & .63 & .26 & .77 & .63 & .37 & .14 & .23 \\
\hline
\end{tabular}

recalled on trial $\mathrm{N}$ in relation to the number of items that were both unrecalled on trial $\mathrm{N}-1$ and selected for study on trial $\mathrm{N}$ (or the mean proportion recalled of items previously unrecalled and selected $), P(R / \bar{R} S)$; (2) the mean proportion recalled of items previously unrecalled and unselected, $\mathrm{P}(\mathrm{R} / \overline{\mathrm{RS}})$; (3) the mean proportion recalled of items previously recalled and selected, $\mathrm{P}(\mathrm{R} / \mathrm{RS})$; (4) the mean proportion recalled of items previously recalled and unselected, $P(R / R \bar{S})$. The group means for each proportion are presented in Table 2. As can be seen in the table, for the three youngest age groups, having remembered an item and having selected an item for study each helped recall, with both combining to produce the greatest recall. For the college-age group, having remembered an item, having selected an item for study, or both, helped recall to a nearly equal degree. Only the college-age group showed substantial recall of items that had been neither selected nor recalled during the previous trial. Turning to the comparative efficiency columns of Table 2 , all four age groups benefited more from selecting missed items (A-B) than from selecting correct items (C-D), with the college-age group showing the least benefit from the latter. Moreover, the third graders, followed by the fifth graders and then the college subjects, derived the most benefit from selecting missed items.

Categorization. Categorization during selection was assessed via the ratio-of-repetition index. The mean ratios obtained during study selection are presented in Table 3. A 4 (age) by 3 (trials) analysis of variance of these ratios revealed a significant effect for age only $[F(3,44)=2.83, p<.05]$. Newman-Keuls comparisons revealed the mean ratio obtained for kindergartners was lower than all the other groups, and those obtained for both third and fifth graders were significantly lower than the mean ratio obtained for the college subjects $(\mathrm{p}<.05)$.

As indicated in Table 3, sign tests revealed that the ratios of repetition obtained for the kindergartners on all three trials and for the third graders on Trial 1 did not differ significantly from chance. Evidently, the kindergartners made little use of categorization as a study strategy and third graders used it only on the second and third trials, whereas the fifth graders and college subjects used it on all three trials.
Categorization efficiency. To assess the mnemonic value of categorizing vs. not categorizing previously missed items during study selection, two efficiency scores were computed: (1) the proportion (averaged over trials) of items recalled on trial $\mathrm{N}$ in relation to the total number of items that were unrecalled on trial $\mathrm{N}-1$ and both categorized and selected for study on trial $\mathrm{N}$ (or the mean proportion recalled of items previously unrecalled and both categorized and selected), $P(R / C \bar{R} S)$; (2) the mean proportion recalled of items previously unrecalled and both uncategorized and selected, $\mathrm{P}(\mathrm{R} / \overline{\mathrm{C}} \overline{\mathrm{R} S})$. The group means for each proportion are given in Table 4. As can be seen in the table, the three youngest age groups were somewhat more efficient in recalling items that were categorized during study selection than those that were not categorized, whereas the college subjects recalled the items about equally well whether or not they were categorized during study selection. Evidently, the strategy of categorizing items together during study selection would be useful to kindergartners if they used it. Surprisingly, this strategy was not particularly useful to the college subjects even

Table 3

Mean Ratio of Repetition Obtained During Study Selection

\begin{tabular}{lcccc}
\hline \multicolumn{1}{c}{ Age Groups } & Trial 1 & Trial 2 & Trial 3 & Mean \\
\hline Kindergarten & .24 & .21 & .23 & .22 \\
Third Grade & .20 & $.35^{*}$ & $.35^{*}$ & .30 \\
Fifth Grade & $.36^{*}$ & $.36^{*}$ & $.37^{*}$ & .36 \\
College & $.51^{*}$ & $.45^{*}$ & $.40^{*}$ & .45 \\
Mean & .33 & .34 & .33 & .33 \\
\hline
\end{tabular}

*Significantly different from chance, sign tests, $p<.05$.

Table 4

Efficiency and Comparative Efficiency of Categorizing vs. Not Categorizing Previously Unrecalled Items During Study Selection

\begin{tabular}{|c|c|c|c|}
\hline \multirow[b]{3}{*}{ Age Groups } & \multicolumn{2}{|c|}{ Efficiency } & \multirow{3}{*}{$\begin{array}{c}\begin{array}{c}\text { Comparative } \\
\text { Efficiency }\end{array} \\
\text { A-B }\end{array}$} \\
\hline & A & B & \\
\hline & $\mathrm{P}(\mathrm{R} / \mathrm{C} \overline{\mathrm{R}} \mathrm{S})$ & $\mathrm{P}(\mathrm{R} / \overline{\mathrm{C}} \overline{\mathrm{R}} \mathrm{S})$ & \\
\hline Kindergarten & .49 & .39 & .10 \\
\hline Third Grade & .68 & .59 & .09 \\
\hline Fifth Grade & .71 & .59 & .12 \\
\hline College & .81 & .80 & .01 \\
\hline Mean & .67 & .59 & .08 \\
\hline
\end{tabular}


though it was used most frequently by them. Interpretation of this result is complicated, however, by ceiling effects in the performance of some of the college subjects.

With respect to the development of study strategies, it is clear that marked qualitative differences are evident between the study strategies used by kindergarten children and those used by third-grade or older children. This is reflected by the contrast between the failure of the kindergarten children to make use of the categorical nature of the stimuli and the success of the older children. As can be seen in Table 3, the kindergarten children showed little inclination to select items for study according to category membership, whereas the older children did. Moreover, as shown in Table 4, if the kindergartners had adopted the strategy of categorizing previously unrecollected items during selection, they might very well have derived as much benefit from this strategy as third and fifth graders. Evidently, the efficiency of kindergartners' recall could be enhanced if the stimulus situation was structured so that they used this strategy. Possibly, this could be done by arranging the stimulus array so that the items in each category were adjacent to each other spatially during study selection. This should lead to greater use of the categorization study strategy by younger subjects and, hence, to better overall recall. Similar results would be expected with the older subjects, but with the expected gains in overall recall performances varying inversely with their "spontaneous" use of the categorization study strategy.

In contrast to the pattern of results obtained for the categorization strategy, the kindergartners derived less benefit from the strategy of selecting unrecalled items for study than did the third and fifth graders (see Table 2), even though they adopted it equally as often (see Table 1). Furthermore, the difference in results observed between the present study and that of Masur et al. (1973) regarding the use of the strategy of selecting unrecalled items for study by the youngest children is intriguing. (Use of this strategy by kindergarten children is indicated by the results of the present study, whereas no evidence of its use by first graders is indicated by the results of the Masur et al. study.) Evidently, the use or nonuse of various study strategies is quite fluid during this formative interval; at present it remains unclear to what extent the adoption of such strategies is sensitive to the demand characteristics of the task and to what extent it may reflect stable developmental differences in the particular populations sampled.

\section{REFERENCES}

Appel, L. F., Cooper, R. G., McCarrell, N., SimsKnight, J., Yussen, S. R., \& Flavell, J. H. The development of the distinction between perceiving and memorizing. Child Development, 1972, 43, 1365-1381.

Bousfield, W. A. The occurrence of clustering in the recall of randomly arranged associates. Journal of General Psychology, 1953, 49, 229-240.

Frender, R., \& Doubilet, P. More on measures of category clustering in free recall-although probably not the last word. Psychological Bulletin, 1974, 81, 64-66.

Masur, E. F., McIntyre, C. W., \& Flavell, J. H. Developmental changes in apportionment of study time among items in a multitrial free recall task. Journal of Experimental Child Psychology, 1973, 15, 237-246.

Moely, B. E., Olson, F. A., Halwes, T. G., \& Flavell, J. H. Production deficiency in young children's clustered recall. Developmental Psychology, 1969, 1, 26-34.

Salatas, H., \& Flavell, J. H. Retrieval of recently learned information: Development of strategies and control skills. Child Development, 1976, 47(4), 941-948.

Yussen, S. R., Gagné, E., Garguilo, R., \& Kunen, S. The distinction between perceiving and memorizing in elementary school children. Child Development, 1974, 45, 547-551.

(Received for publication March 1, 1978.) 